\title{
Key Issues for Seamless Integrated Chemistry-Meteorology Modeling
}

\author{
Alexander Baklanov, Dominik Brunner, Gregory Carmichael, Johannes Flemming, \\ Saulo Freitas, Michael Gauss, Øystein Hov, Rohit Mathur, K. Heinke Schlünzen, \\ Christian Seigneur, and Bernhard Vogel
}

$\mathrm{N}$ umerical models that couple meteorology with atmospheric chemistry and aerosol dynamics within one integrated model system have undergone a rapid evolution in recent years. The motivation for this development is the recognition that not only does meteorology have a strong impact on air quality, but also, in return, weather and climate respond to changes in atmospheric composition. Of particular importance are the interactions between weather/ climate and aerosols, which are key air pollutants and at the same time affect the radiative balance of the atmosphere and the formation of clouds and precipitation.

The European Cooperation in Science and Technology (COST) Action ES1004 EuMetChem (European Framework for Online Integrated Air Quality and Meteorology Modeling, 2011-15) aimed at developing a strategy and framework for online integrated modeling by identifying relevant interactions, parameterizations, and feedback mechanisms and by considering chemical data assimilation in integrated models. The status of integrated modeling has been extensively summarized by Baklanov et al. (2014), and a large number of regional modeling systems have been thoroughly evaluated in the joint European-North American initiative, AQMEII-2 (Galmarini et al. 2015). The action included experts not only from Europe but also from other continents. In February 2015, a EuMetChem closing symposium on "Coupled Chemistry-Meteorology/Climate Modelling (CCMM): Status and relevance for numerical weather prediction, atmospheric pollution and climate research" was organized at the World Meteorological Organization (WMO) and hosted by the Global Atmospheric Watch program, attracting more than 100 scientists from 5 continents. ${ }^{1}$

Based in part on discussions at that symposium, we synthesize the scientific progress by answering nine key questions and providing recommendations for future research directions and priorities for the development,

\footnotetext{
${ }^{1}$ In addition to a detailed meeting report (WMO CCMM 2016), selected papers presented at the conference are gathered in the joint CCMM/EuMetChem special issue of Atmospheric Chemistry and Physics and Geoscientific Model Development (Baklanov et al. 2015). Most presentations are available at www.eumetchem.info/ccmm.html.
}

AFFILIATIONS: BAKLANOV-World Meteorological Organization, Geneva, Switzerland, and Danish Meteorological Institute, Copenhagen, Denmark*; BrUnNer-Empa, Swiss Federal Laboratories for Materials Science and Technology, Dübendorf, Switzerland; CARMICHAEL-University of lowa, lowa City, lowa; FLEMMING-European Centre for Medium-Range Weather Forecasts, Reading, United Kingdom; FreItAS-NASA Goddard Space Flight Center, Greenbelt, Maryland; Gauss And HovNorwegian Meteorological Institute, Norway; MATHUR-U.S. Environmental Protection Agency, Research Triangle Park, North Carolina; SCHLÜNZEN-Meteorological Institute, University of Hamburg, Hamburg, Germany; SEIGNEUR-CEREA, Joint Laboratory École des Ponts ParisTech/EDF R\&D, Université
Paris-Est, Paris, France; VogeL-Karlsruhe Institute of Technology, Karlsruhe, Germany

*On leave

CORRESPONDING AUTHOR: Gregory Carmichael, gcarmich@engineering.uiowa.edu

The abstract for this article can be found in this issue, following the table of contents.

DOI:10.1175/BAMS-D-I5-00166.I

C2017 American Meteorological Society

For information regarding reuse of this content and general copyright information, consult the AMS Copyright Policy. 
application, and evaluation of online coupled models for three main application areas: air quality, meteorology (including weather prediction), and climate modeling.

WHAT WOULD MOVING TO INTEGRAT-
ED MODELING SYSTEMS DO FOR THE
COMMUNITY? Migration from offline to online integrated modeling systems is recommended, as only the latter approach can guarantee a consistent treatment of processes and allow two-way interactions of physical and chemical components, particularly for air quality (AQ) and NWP communities. Applications that may benefit from CCMM are numerous and include the following: chemical weather forecasting (CWF); numerical weather prediction for precipitation, visibility, thunderstorms, etc.; integrated urban meteorology, environment, and climate services; sand and dust storm modeling and warning systems; wildfire atmospheric pollution and effects; volcano ash forecasting, warning, and effects; high-impact weather and disaster risk; effects of short-lived climate forcers; Earth system modeling and projections; data assimilation for CWF and NWP; and weather modification and geoengineering. Online integrated models, however, need harmonized and seamless formulations of all processes influencing meteorology and chemistry as discussed below.

WHAT ARE THE ADVANTAGES OF IN-
TEGRATING METEOROLOGICAL AND
CHEMICALIAEROSOL PROCESSES IN
COUPLED MODELS? Meteorological processes such as thunderstorms, radiation, visibility, and planetary boundary layer (PBL) structure are all affected by atmospheric concentrations of chemical components, especially aerosols. The effects of aerosols are relevant in air quality modeling, in the prediction of tomorrow's temperatures and precipitation, and in sensitive applications such as cloud and fog forecasting for aviation. However, the relevance of aerosol effects for operational NWP applications has not yet been thoroughly demonstrated, except for short episodes associated with high aerosol concentrations such as dust outbreaks or intense biomass burning (Rémy et al. 2015; Freitas et al. 2016). For cloud properties, having online aerosols is most probably an advantage, while for precipitation the benefits are not yet clear. It is also unclear whether the advantages demonstrated for short-term episodes with extreme aerosol loading are still present in more common situations relevant for daily weather prediction.
A proper representation of aerosols in NWP models may also be beneficial for the assimilation of satellite observations, since aerosols affect the path of light through the atmosphere and may therefore affect the retrieval of temperatures, water vapor, ozone, and other parameters from satellite-observed radiances.

Several case studies have shown the benefits of including aerosols in NWP models for the prediction of surface temperature and radiation during episodes of high aerosol concentrations. Aerosols have also been shown to affect wind speeds through their interaction with local stratification and convection, and to influence cloud formation and precipitation. The effects over more extended periods of time could be important under changing emission scenarios but need to be examined in more detail. Some improvements in model skill for predicting standard weather variables-such as screen-level temperature, cloud, and winds-have been shown. In many cases there are improvements for these variables but certainly not under all meteorological situations, and the improvement also depends on the application. For example, the integration may be more relevant for issues such as aircraft and surface icing and light precipitation than for heavy precipitation.

Integration of meteorological and chemical/aerosol processes into a single forecasting system is assumed to be most important for atmospheric chemical transport (ACT) modeling (air quality/atmospheric composition) and climate applications. As for short-range limited-area NWP models, the essential aspect is to be able to obtain reliable (3D) real-time aerosol concentrations. This can be presently used for aerosol direct radiative effects, and in the future for improved parameterizations of cloud microphysics for precipitation.

A technical advantage of online coupled systems is the reduced amount of work needed to maintain and further develop the model, since processes like advection or diffusion can be calculated with the same methods (e.g., for water vapor or other concentration), and even the same code can be used. However, offline modeling systems in some cases require lower computational resources-for example, for air quality regulatory assessments when the meteorological output is already available from multiple emission scenarios or analysis runs. Grell and Baklanov (2011) pointed out the main strengths and disadvantages of both approaches.

Ultimately, there is need for (field experimental) data to evaluate online coupled models. In addition, we will need more collaboration between operational NWP centers and research communities. This needs 
to be focused on providing schemes that have an impact that is proven to be valuable enough to justify the cost of their implementation (even for relatively modest increases in CPU). Overall, intercomparisons at both global and regional scale for AQ, NWP, and climate should continue, and intercomparisons that cut across all three fields should be considered.

HOW IMPORTANT ARE THE TWO-WAY FEEDBACKS AND CHAINS OF FEEDBACKS FOR METEOROLOGY, CLIMATE, AND AIR QUALITY SIMULATIONS? The

processes, which are particularly critical for online coupling between the chemical and meteorological components, include i) advection, convection, and vertical diffusion (which control the transport and dispersion of chemical species and hence critically affect surface concentrations); ii) cloud microphysics (which determines cloud life cycle and interactions between clouds and aerosols, and affects soluble chemical species); iii) radiative transfer (which is determined by meteorological parameters and radiatively active chemical compounds); and iv) turbulent fluxes at the surface (which influence transport and dry deposition of chemical species). The importance of these interactions depends on the meteorological parameters being considered and the prevalent conditions. While the importance of aerosol loading for estimating surface shortwave radiation is clear, there is more uncertainty in quantifying the effects of aerosols on cloudiness. It seems quite probable that it is important to represent these, as well. In the case of precipitation, the importance (e.g., the impact direction) is not yet clear.

Research has shown that meteorology and chemistry feedbacks can be important, but there are still many unanswered questions to specify how important they are. There is strong evidence for the importance of some chains of interactions-for example, increased aerosol loadings lowering surface temperature, thereby reducing boundary layer depth and increasing primary pollutant concentrations at the surface. However, the importance of these chains is less clear under normal conditions than in the strong events considered in many studies, such as Xing et al. (2015).

The importance of coupling may also be seen at the sea surface. Coupling with oceans is important for both atmosphere and ocean: the impact of aerosols on sea surface temperature can only be considered with prognostic aerosol models, and links to biogeochemistry in the ocean are relevant to determine emissions, especially dimethyl sulfide (DMS).
There is also emerging evidence that the importance of the aerosol feedback on meteorological processes is not only dependent on aerosol loading but also on the region (e.g., for polar, desert, or tropical regions). Grell and Freitas (2014) and WMO CCMM (2016) indicated that the cloud-aerosol interaction may be more important in the tropics.

The relative importance of online integration and of the priorities, requirements, and level of detail necessary for representing different processes can vary greatly between applications (i.e., NWP, AQ, or climate and Earth system modeling). Most current NWP models do not incorporate detailed aerosol processes, even though aerosols-via radiative and microphysical mechanisms - can affect fog formation, visibility, and precipitation, and thus forecasting skill. Research is needed on the impact of online modeling of aerosols on visibility forecasting, observational constraints on the causes of light extinction, and on parameterizations for calculating extinction given model parameters.

The impact of modified NWP forecasts of 3D meteorological variables on real-time AQ forecasts could be estimated by online coupled ACT models. For weather prediction by short- to medium-range NWP models, the 3D real-time aerosol would most probably be important in specific cases of high aerosol concentrations. The task of the NWP community is first of all to make sure the radiation and microphysics parameterizations will be able to optimally use this information when obtained as climatological fields or as forecast fields from another model.

Under particular circumstances, the two-way feedbacks can be very important: Saharan dust and biomass burning aerosols have been reported to be able to reduce downward shortwave radiation by several tens and up to $100 \mathrm{~W} \mathrm{~m}^{-2}$ locally with correspondingly large effects on surface temperatures and vertical stability (Mallet et al. 2009; Kong et al. 2014; Rémy et al. 2015).

Within the climate community, two-way feedbacks are of crucial importance to correctly capture climate sensitivity. Important feedbacks for climate and the other modeling communities have been identified by the COST Action ES1004.

\section{WHAT ARE THE EFFECTS OF METEO- ROLOGY ON THE ABUNDANCE AND PROPERTIES (CHEMICAL, MICROPHYSI- CAL, AND RADIATIVE) OF AEROSOLS ON URBAN-REGIONAL-GLOBAL SCALES?}

Many processes relevant for air quality depend on meteorological conditions. Some examples include the 
importance of wind and turbulence for the release of dust and sea salt aerosols, humidity for dry deposition, temperature for volatile organic compound (VOC) emissions, cloud processes for aqueous chemistry and wet deposition, and moisture and temperature for fire emissions. Rémy et al. (2015) showed how changes in boundary layer stability may feed back on low-level wind speed and thus on dust emissions. The formation of secondary aerosols depends on temperature, UV radiation, and relative humidity. Some of these effects of meteorology on emissions and air quality can already be accounted for in offline coupled models. In addition, online coupled models consider further feedbacks and chains of interactions (from meteorology to emissions to atmospheric aerosols and back to meteorology, and so on), such as the modification of radiation by aerosols and gases, and indirect aerosol feedback effects, such as the modification of physical properties of clouds followed by modifications of radiation and precipitation. In addition, this implies changes of the light reaching the surface and changes of the oxidation and formation of secondary aerosols near the surface. These second-order effects become important as the aerosol concentrations increase. Quantification of these second-order effects is relevant to the question of whether they are important for weather forecasting. This seems to be the case for longer-term comparisons (not only for specific episodes, but also multiyear validation studies) and for large deviations from the mean aerosol loading, but the effects are often in the range of model-model differences and therefore difficult to demonstrate (Kong et al. 2014).

Effects known for climate include, for example: i) less precipitation and higher wind speeds lead to higher aerosol dust and sea salt emissions, ii) changes in humidity alter wet scavenging and resuspension of aerosol, iii) changes in circulation/wind patterns alter aerosol transport and abundances, iv) climate change caused by changes in aerosols affects other chemical constituents such as tropospheric and stratospheric ozone, v) changes in cloudiness affect photolysis rates, and vi) long-term dry and hot climates increase flammability of vegetation and fire emissions.

WHAT IS OUR CURRENT UNDERSTANDING OF AEROSOL-CLOUD INTERACTIONS AND HOW WELL ARE RADIATIVE FEEDBACKS REPRESENTED IN NWP/CLIMATE MODELS? Generally speaking, shortwave radiation in existing modern CCMMs is perhaps the best represented radiative feedback process, while longwave radiation is less well represented and cloudaerosol interactions are poorly described. However, the level of sophistication differs from one model to another.

The indirect effects seem to be very sensitive to the sophistication of the chosen parameterizations and to the detail of the implementation. The models participating in phase 2 of the Air Quality Modeling Evaluation International Initiative (Galmarini and Hogrefe 2015) employing essentially the same theoretical approaches for cloud condensation nuclei (CCN) sometimes had very different results. Idealized model sensitivity studies on isolated clouds show a clear aerosol effect, while in more realistic simulations the atmospheric feedback is more complex, including chains of interactions with many other processes and with compensating effects. The large scatter in plots of laboratory data of particles' capability to act as ice nuclei shows that this is a topic for more research.

In NWP, it will be important to develop diagnostics and validation methodologies to more explicitly separate the different effects of the intertwined feedback processes. With respect to climate modeling, cloud-aerosol interactions are also not yet fully understood, in particular for ice clouds and mixedphase clouds including midlevel and Arctic clouds.

Certainly, experiments are needed that are specifically defined to look at chemistry-cloud microphysics at different scales. And the numerical and computational efficiency of the models will need to improve as the complexity of applications grows (e.g., scales).

Similarly, the climate community will need to develop CCMs with prognostic aerosol, which means the level of sophistication of such modules needs to be defined. For example, what is the trade-off between a more complex aerosol representation on the one side and model resolution, or the atmosphere-ocean coupling, on the other side? In addition, the consistency between resolution and parameterizations needs to be assessed.

\section{WHAT IS THE RELATIVE IMPORTANCE OF THE DIRECT AND INDIRECT AERO- SOL EFFECTS, AS WELL AS OF GAS- AEROSOL INTERACTIONS, FOR DIFFER- ENT APPLICATIONS (E.G., FOR NWP, AIR QUALITY, CLIMATE)? For NWP, the direct ra- diative aerosol effect is probably the most important feedback mechanism. The indirect one comes sec- ond (or first according to some authors depending on meteorological situations they consider), while}


gas-aerosol interactions are rated not important (but they are important if we consider secondary aerosol formation). Aerosols are very important for cloud microphysics; therefore, they might be important for precipitation forecasting. The definition and specification of indirect effects is a complicated issue that deserves further attention and requires clear diagnostics for evaluation due to the lack of such observations and verification methods for online coupled models.

The direct and indirect effects sometimes have opposite impacts on both weather and air quality predictions, so their integrated effect can be different. For specific aerosol episodes under cloudy conditions the indirect effect can be the dominant process, but the cross-model variability in the implementation of the indirect effect complicates comparisons of their relative specific impacts. A global reference set of aerosols and their properties would be very useful in aiding the comparison of the indirect effects across models. This could perhaps be developed from CAMS reanalyses or other long-term model runs [e.g., within the ongoing European Union project Impact of Biogenic versus Anthropogenic Emissions on Clouds and Climate: Towards a Holistic Understanding (BACCHUS)].

For climate studies, the question as to which effect is of highest relevance depends on the region and the season (e.g., during polar nights the direct effects into the boundary layer are not so critical). Both the direct and indirect effects are important for climate applications, but the largest uncertainty comes from the indirect effect, in particular aerosol effects on ice clouds. Using aerosol climatologies instead of predicted aerosols, due to their strong temporal and spatial inhomogeneity, may cause significant errors in satellite retrievals of some gases such as ozone.

The climate community needs to improve our understanding of indirect effects (e.g., black carbon on clouds). The details of implementation of the indirect effect have a large impact on model results, and hence should be a focus of future research. Complete analysis of indirect effects will require simulations on high resolution and aerosol representations in convective schemes.

Accounting for feedback effects can influence the assessment of the impact of emission changes on air quality. Ensemble estimates present a viable means to balance the diversity and accuracy of existing CCMMs for air quality applications.
WHAT ARE THE KEY UNCERTAINTIES ASSOCIATED WITH MODEL PREDIC. TIONS OF FEEDBACK EFFECTS? The treatment of the indirect effect is one of the key uncertainties. Ice nucleation processes and parameterizations are less well defined than CCN parameterizations.

For the direct effect, accurate estimation of aerosol optical properties is largely dictated by the accurate prediction of aerosol composition, size distribution and mixing state, and the knowledge of the refractive index of the individual species. So this requires increasing the accuracy of aerosol dynamics models able to predict these factors.

Feedback effects seem to have a crucial importance in the vicinity of large emission sources (Saharan dust, forest fires, and other large plume emissions), but the parameterizations for these emission sources do not always explicitly include feedback effects, and for forest fires, the parameterizations for plume rise are many and variable in their accuracy. To get feedbacks "right," better parameterizations for these sources are needed, or feedbacks need to be explicitly included in their formulation.

Key uncertainties for NWP are: 1) How to parameterize the shortwave and longwave radiation transfer, and 2) how to obtain reliable real-time external aerosol. There are a lot of uncertainties around the indirect aerosol effects, but perhaps for NWP they are not "key," as it is not so easy to take these into account, and the importance of doing so is unknown from the NWP perspective.

Key uncertainties for climate are: 1) Measuring feedback processes in reality (and verifying them in models) is a challenge, and so is the quantification of uncertainties; key uncertainties may lie in cloudaerosol couplings, as this will potentially have a large impact on climate. 2) Biosphere-atmosphere couplings will also respond to climate change and are not fully understood. 3) Radiative forcing is a poor measure for regional climate response (feedback effects seem to have a crucial importance in the vicinity of large emission sources).

HOW CAN CHEMICAL DATA ASSIMILATION BE IMPLEMENTED IN INTEGRATED MODELS TO IMPROVE NWP AND AIR QUALITY SIMULATIONS? During the last decade, experience in assimilation of chemical and aerosol observations from ground-based and satellite instruments into CCMM has grown 
significantly (Bocquet et al. 2015; Ch.12 in WWRP 2015). Chemical data assimilation (DA) has been implemented in several CCMM, such as the Integrated Forecast System (IFS), the Weather Research and Forecasting Model coupled with chemistry (WRFChem), and the Goddard Earth Observing System Model, version 5 (GEOS-5). Chemical DA is used to initialize air quality forecasts and for retrospective analysis of atmospheric composition. It has been shown that corrections to emissions as part of the DA procedure (additionally to model validations) can help improve the impact of the observations on the predictions.

A main challenge of chemical DA is the limited information content of the atmospheric composition observations (Table 1). We need more routine evaluation of aerosol properties, not only for the indicators $\mathrm{PM}_{10}$ and $\mathrm{PM}_{2.5}$, but also for optical, chemical, and microphysical properties. Meanwhile, spatial and temporal coverage of important parameters such as aerosol composition is limited because of network design, viewing geometry, or cloud cover masking. Also, vertically integrated observations, such as aerosol optical depth or total column, have to be distributed to model levels. Furthermore, biases between different observing systems (e.g., satellite data, lidars, ceilometers, ground observations) should be removed before the assimilation.

Although the importance of assimilating atmospheric composition data into CCMM to get realistic chemical fields has been demonstrated, there is little experience in assimilation of both meteorological and chemical observations into CCMM. Further research is needed to better understand the importance of including more accurate representation of aerosol properties in satellite retrievals.

Also, future research should address cross correlations between chemical and meteorological background errors (e.g., wind vs chemical species and species vs species). Better characterization of these cross correlations will extend the power of the assimilated data to improve predictions, as many parameters have relations that can be exploited. For example, many biogeochemical surface fluxes (e.g., $\mathrm{CO}_{2}, \mathrm{NH}_{3}$, isoprene) are dependent on surface temperature, wind speed, solar radiation, and soil moisture. Furthermore, various species share common emission sources (e.g., biomass burning has high emissions of black carbon, carbon monoxide, and carbon dioxide). Thus, the power of observations of variables such as carbon dioxide and soil moisture can be extended to impact a whole host of variables. Meanwhile, we will also need development of new observing systems such as lidars and geostationary instruments for atmospheric composition observations.

\section{HOW CAN THE SIMULATED FEEDBACKS BE VERIFIED WITH AVAILABLE OBSERVA- TIONS/DATASETS? WHAT ARE THE RE- QUIREMENTS FOR OBSERVATIONS FROM THE THREE MODELING COMMUNITIES?}

No robust evaluation has been performed to answer these questions, in large part because of the paucity of simultaneous measurements of aerosol chemical, optical, and radiative properties. However, existing and further planned radiation measurements at the surface could be used more widely for validation of NWP and climate models, which always parameterize the radiation fluxes and include them in the model output. For NWP, as well as for the other two modeling communities, there is the question of developing model diagnostics and validation for high-resolution CCMMs, where quite a lot of work is being done (see WMO CCMM 2016).

Nudged climate simulations help verification, although some of the feedback effects (e.g., aerosol indirect effects) will be suppressed by the nudging. The skill scores of meteorological and composition variables for free-running simulations where feedbacks are on/off can be compared.

We will need to test model performance in terms of relevant physical, chemical, and radiative processes and mechanisms (going beyond just testing mean performance). In particular, NWP models are tuned to perform well without feedbacks, leaving much room for improvement toward more realistic model behavior. We will also need to test model performance in terms of tropospheric dynamics/ meteorology and their effect on composition (and vice versa). This is important especially in the field of inverse modeling of emission sources. Also, the models should continue to be compared at both global and regional scale for AQ, NWP, and climate. Intercomparisons that are cutting across all three fields should be considered.

Modelers usually take the observations that are available without specifically addressing the requirements for new or enhanced observations. This lack of observations is a challenge for many steps in the chains of interacting processes. Thus, some advice from those three communities-NWP, air quality, 
TABLE I. WMO CCMM (2016) report mentioned the following measurement/instrumentation needs.

\begin{tabular}{|c|c|}
\hline Variables & Measurement/instrumentation needs \\
\hline Aerosol sizing & Optical particle counters and mobility particle size spectrometers \\
\hline Aerosol composition & $\begin{array}{l}\text { Analysis of filter sample, filterpack, aerosol mass spectrometers, } \\
\text { elemental carbon/organic carbon analyzers }\end{array}$ \\
\hline Aerosol optical properties & Aethalometer, nephelometer \\
\hline Aerosol nucleation & $\begin{array}{l}\text { Condensation particle counters, size resolved CCN, Zurich lce } \\
\text { Nucleation Chamber, tandem differential mobility analyzers }\end{array}$ \\
\hline Radiation & $\begin{array}{l}\text { Downward and upward shortwave and longwave radiation, } \\
\text { diffuse/direct components }\end{array}$ \\
\hline Aerosol remote sensing & AOD, absorption AOD, Angstrom exponent, fine fraction \\
\hline Cloud properties & Cover, optical depth, liquid/ice water path, droplet/ice number concentration \\
\hline Radiative fluxes & In the atmosphere and at the surface \\
\hline Turbulent fluxes & In the atmosphere and at the surface \\
\hline Information on PBL height/stratification & Time dependent, spatially resolved \\
\hline
\end{tabular}

and climate-would be beneficial: what are the measures of significance of a model change, relative to observations, typically employed in these communities? As well as providing more observations, it would be very helpful if meteorological services and institutes could provide better access to datasets such as shortwave radiation or cloud observations that are not routinely reported to the international weather centers. More vertical profiling in the boundary layer is also a key, as often the largest modeled changes are not at the surface but higher up in the atmosphere.

There is a need for collocated and simultaneous meteorology and chemistry measurements at locations carefully selected to ensure spatial representativeness. To really drill down into the processes, more sites with collocated observations of visibility, cloud, radiation, vertical profiles of temperature, and relative humidity, as well as winds and aerosol properties, would be highly desirable. Innovative designs for global measurement systems (using existing platforms such as commercial aircraft, cell phones, cars, etc.) should be further exploited. Such a task should fit the mandate of international organizations such as WMO and the European Meteorological Network (EUMETNET).
ACKNOWLEDGMENTS. The COST Action ES1004 EuMetChem and the World Meteorological Organization, which organized the CCMM Symposium, are greatly acknowledged. The authors thank the symposium organizers, session chairs, and participants. In addition, we thank the seven brainstorming teams who reported on the following topics: 1) coupled chemistry-meteorology systems [Greg Carmichael (chair), Georg Grell, Peter Suppan, Alexander Baklanov]; 2) key processes [Bernhard Vogel (chair), Paul Makar, Renate Forkel, Yang Zhang]; 3) CCMMs for climate studies [Øystein Hov (chair), Michel Rixen, Michael Gauss, Annica Ekman, Michaela Hegglin]; 4) CCMMs for air quality and atmospheric composition [Rohit Mathur (chair), Veronique Bouchet, Nicolas Moussiopoulos, Jose M. Baldasano, Ana Isabel Miranda]; 5) CCMMs for NWP and meteorology [Saulo Freitas (chair), Sylvain Joffre, Vincent-Henri Peuch, Nick Savage]; 6) model evaluation [Heinke Schlünzen (chair), Dominik Brunner, S.T. Rao, Stefano Galmarini]; and 7) data assimilation [Christian Seigneur (chair), Johannes Flemming].

\section{FOR FURTHER READING}

Baklanov, A., and Coauthors, 2014: Online coupled regional meteorology chemistry models in Europe: 
Current status and prospects. Atmos. Chem. Phys., 14, 317-398, doi:10.5194/acp-14-317-2014.

_ , B. Vogel, and S. Freitas, Eds., 2015: Coupled chemistry-meteorology modelling: Status and relevance for numerical weather prediction, air quality and climate communities. Special issue jointly organized between Atmos. Chem. Phys. and Geosci. Model Dev. [Available online at www.atmos-chem-phys.net/specia _issue370.html.]

Bocquet, M., and Coauthors, 2015: Data assimilation in atmospheric chemistry models: Current status and future prospects for coupled chemistry meteorology models. Atmos. Chem. Phys., 15, 5325-5358, doi:10.5194/acp-15-5325-2015.

Freitas, S. R., and Coauthors, 2016: Evaluating aerosols impacts on numerical weather prediction: 3rd report. [Available online at http://polar.ncep.noaa. gov/conferences/WGNE-30/pdfs/day3/03-Freitas -Aerosols.pdf.]

Galmarini, S., and C. Hogrefe, Eds., 2015: Evaluating Coupled Models (AQMEII P2). Special Issue Section. Atmos. Environ., 115, 340-775, doi:10.1016/j .atmosenv.2015.06.009.

,-- D. Brunner, P. Makar, and A. Baklanov, 2015: Evaluating Coupled Models (AQMEII P2): Preface. Atmos. Environ., 115, 340-344, doi:10.1016/j.atmosenv .2015.06.009.

Grell, G. A., and A. Baklanov, 2011: Integrated modelling for forecasting weather and air quality: A call for fully coupled approaches. Atmos. Environ., 45, 6845-6851, doi:10.1016/j.atmosenv.2011.01.017.

_ , and S. R. Freitas, 2014: A scale and aerosol aware stochastic convective parameterization for weather and air quality modeling. Atmos. Chem. Phys., 14, 5233-5250, doi:10.5194/acp-14-5233-2014.

Kong, X., and Coauthors, 2014: Analysis of meteorologychemistry interactions during air pollution episodes using online coupled models within AQMEII phase-2. Atmos. Environ., 115, 527-540.

Mallet, M., P. Tulet, D. Serça, F. Solmon, O. Dubovik, J. Pelon, V. Pont, and O. Thouron, 2009: Impact of dust aerosols on the radiative budget, surface heat fluxes, heating rate profiles and convective activity over West Africa during March 2006. Atmos. Chem. Phys., 9, 7143-7160, doi:10.5194/acp-9-7143-2009.

Rémy, S., and Coauthors, 2015: Feedbacks of dust and boundary layer meteorology during a dust storm in the eastern Mediterranean. Atmos. Chem. Phys., 15, 122 909-122 933, doi:10.5194/acp-15-12909-2015.

WMO CCMM, 2016: Coupled Chemistry-Meteorology/ Climate Modelling (CCMM): Status and relevance for numerical weather prediction, atmospheric pollution and climate research (Symposium materials). WMO GAW Report, Geneva, Switzerland. [Available online at www.wmo.int/pages/prog/arep/gaw/documents /Final_GAW_226_10_May.pdf.]

WWRP, 2015: Seamless Prediction of the Earth System: From Minutes to Months. WMO-No. 1156. 471 pp. [Available online at http://library.wmo.int/pmb_ged /wmo_1156_en.pdf.]

Xing, J., R. Mathur, J. Pleim, C. Hogrefe, C.-M. Gan, D. C. Wong, and C. Wei, 2015: Can a coupled meteorology-chemistry model reproduce the historical trend in aerosol direct radiative effects over the Northern Hemisphere? Atmos. Chem. Phys., 15, 9997-10,018, doi:10.5194/acp-15-9997-2015. 